\title{
Perencanaan Struktur Gedung Fakultas Teknik Universitas Moren Jalan Kranggan Semarang
}

\author{
Reinard Sutanto; Willya Moren; \\ David Widanto dan Budi Setiyadi \\ e-mail: reinadsut001@gmail.com \\ Program Studi Teknik Sipil, Fakultas Teknik \\ Universitas Katolik Soegijapranata, Semarang
}

\begin{abstract}
The construction of engineering faculty at the university of moren can be may be able to meet terms of education facilities.Building of engineering faculty university of moren is school buildings, so that including buildings class viii.The building has six floors of with total building area of $11.664 \mathrm{~m}^{2}$.The roof of the building planned use of concrete plate.The shear wall planned in central structure of the floor ground until the floor 5 to hold earthquake force direction $x$ of $7609 \mathrm{~kg} . \mathrm{m}$ and direction y of $6879 \mathrm{~kg} . \mathrm{m}$

A structure for the faculty engineering university moren use 03-1726-2012 sni, SNI T-151991-03, sni 2847-2013, SNI03-1965-1990, and SNI 07-2529-1991.Planning the structure down include the stake, tiebeam, pilecap. While stuktur upper covering concrete plate, floor plates, stairs, beam, column, and shearwall .In counting the moments and reaction on buildings it uses 2000 v.14 sofware sap

The results of result in planning the plate with thick $20 \mathrm{~cm}$ to floor ground and $12 \mathrm{~cm}$ pelat 1 until 5 to the floor and the roof. Design planning a beam B1 $=450 \times 700, B 2=350 x$ $500, B 3=350 \times 600, B 4=300 \times 450$. Design planning a column $K 1=800 \times 800$. Design planning foundation piles $50 \mathrm{~cm}$ in the depth 18 meters .
\end{abstract}

Keyword: Planning, building structures, , Structure Analysis Program (SAP) V.14, earthquake

\section{Pendahuluan}

\subsection{Latar Belakang}

Seiring berkembangnya jaman, semakin meningkat pula kesadaran masyarakat akan pentingnya melanjutkan pendidikan ke-jenjang yang lebih tinggi lagi. Kebutuhan akan pendidikan di jaman modern ini dapat digolongkan juga sebagai kebutuhan primer bagi manusia dewasa.

Dengan tingginya kebutuhan pendidikan bagi manusia dewasa ini, maka kebutuhan akan bangunan yang dapat memfasilitasi dalam menimba ilmupun semakin dibutuhkan. Oleh karena itu, pembangunan fakultas teknik di Universitas Moren diharap dapat mengurangi kebutuhan manusia yang dapat membangun kebutuhan bangunan tersebut.

\subsection{Lokasi Proyek dan Data Teknis}

Proyek pembangunan Gedung ini secara geografis letak bangunannya dibatasi oleh:

a.Sebelah Utara: Rumah warga

b.Sebelah Timur: Queen cake and bakery dan Hotel Semesta

c.Sebelah Barat: Rumah warga

d.Sebelah Selatan: J1. K. H. Wahid Hasyim

Data teknis Proyek pembangunan Gedung Fakultas Teknik Universitas Moren Semarang sebagai berikut : 
1. Luas Lahan

$: 2.400 \mathrm{~m}^{2}$

2. Luas Bangunan $: 11.664 \mathrm{~m}^{2}$

3. Jumlah Lantai : 6 Lantai

\subsection{Tujuan Penulisan Tugas Akhir}

Tujuan yang henpelat dicapai dari penyusunan tugas akhir ini yaitu:

1. Mahasiswa dapat menerapkan ilmu perencanaan dan perhitungan struktur bangunan bertingkat yang telah diperoleh selama ini di bangku perkuliahan Program Studi Teknik Sipil

2. Mampu menerapkan perhitungan dengan teliti dan tepat sehingga diperoleh gedung yang ekonomis dan aman

3. Mahasiwa mampu menggunakan program AUTOCAD 2010 untuk penggambaran struktur dan program System Analysis and Program Develpoment (SAP) 2000 v.14 untuk perhitungan mekanika struktur pada penyelesaian tugas akhir perencanaan struktur.

\section{Tinjauan Pustaka}

\subsection{Uraian Umum}

Perencanaan gedungFakultas Teknik Universitas Moren Semarang terdiri dari enam lantai ini merupakan gedung bertingkat tinggi sehingga perlu memenuhi empat kriteria utama yaitu:

1. Ketetapan

Kriteria ini meliputi tata letak ruang dalam gedung, bentang, ketinggian plafon, serta segi estetika yang sesuai dengan persyaratan yang ada,

2. Persyaratan struktur

Struktur yang digunakan harus:

Kuat: Struktur mampu menerima beban-beban yang bekerja baik beban vertikal maupun lateral yang disebabkan oleh gempa serta kestabilan struktur dalam dua kedua arah tersebut.

Nyaman: Struktur tipelat mengalami kegagalan struktur mulai dari lendutan, getaran, retak secara berlebihan sehingga mengganggu kegunaan bangunan.

Awet:Struktur yang telah direncanakan dan dibangun diharap dapat memiliki daya layan yang baik sehingga gedung dapat digunakan dalam jangka waktu yang lama.

3. Ekonomis

Pendemensian (ukuran struktur) yang proposional dan pemakaian bahan yang sesuai sehingga bangunan awet mempunyai umur yang panjang, dan pemeliharaan yang mudah dan dapat lebih ekonomis.

\subsection{Modifikasi Perencanaan Gedung}

Perencanaan gedung fakultas teknik Universitas Moren ini merupakan perencanaan ulang yaitu hasil modifikasi atau re-design dari perencanaan aslinya. Modifikasi dilakukan di sebagian besar bangunan mulai dari struktur atas hingga struktur bawah.

Modifikasi yang dilakukan dengan mengganti ukuran jarak antar kolom yang semula $5 \mathrm{~m} \times 5 \mathrm{~m}$ menjadi $6 \mathrm{~m} \times 6 \mathrm{~m}$.

\subsection{Tinjauan Pustaka}

\subsubsection{Peraturan-Peraturan}

Untuk perhitungan konstruksi gedung ini mengacu pada ketentuan-ketentuan yang berlaku pada peraturan pedoman antara lain:

1. Kombinasi beban untuk metoda ultimit (SNI 03-1726-2012)
a. $\mathrm{U}=1,4 \mathrm{D}$
b. $\mathrm{U}=1,2 \mathrm{D}+1,6 \mathrm{~L}+0,5\left(\mathrm{~L}_{\mathrm{r}}\right.$ atau $\left.\mathrm{R}\right)$
c. $\mathrm{U}=1,2 \mathrm{D}+1,6\left(\mathrm{~L}_{\mathrm{r}}\right.$ atau $\left.\mathrm{R}\right)+(\mathrm{L}$ atau $0,5 \mathrm{~W})$
d. $\mathrm{U}=1,2 \mathrm{D}+1,0 \mathrm{~W}+\mathrm{L}+0,5$ (Lratau $\mathrm{R})$
e. $U=1,2 \mathrm{D}+1,0 \mathrm{E}+\mathrm{L}$
f. $U=0,9 \mathrm{D}+1,0 \mathrm{~W}$
g. $U=0,9 \mathrm{D}+1,0 \mathrm{E}$

Keterangan:
U $\left(\mathrm{kg} / \mathrm{m}^{2}\right)$ adalah kekuatan yang dibutuhkandalam menahan beban terfaktor, momen dan gaya.


D $\left(\mathrm{kg} / \mathrm{m}^{2}\right)$ adalah beban mati

L $\quad\left(\mathrm{kg} / \mathrm{m}^{2}\right)$ adalah beban hidup

$\mathrm{L}_{\mathrm{r}} \quad\left(\mathrm{kg} / \mathrm{m}^{2}\right)$ adalah beban hidup atap

E $\left(\mathrm{kg} / \mathrm{m}^{2}\right)$ adalah beban gempa (SNI 031726-2012)

$\mathrm{R}\left(\mathrm{kg} / \mathrm{m}^{2}\right)$ adalah beban hujan

$\mathrm{W}\left(\mathrm{kg} / \mathrm{m}^{2}\right)$ adalah beban angin

S $\left(\mathrm{kg} / \mathrm{m}^{2}\right)$ adalah beban salju

\subsubsection{PembebananGempa Menggunakan Analisa Statik Ekivalen}

Beban gempa adalah semua beban statik ekivalen yang bekerja pada gedung atau bagian gedung yang menirukan pengaruh dari gerakan tanah akibat gempa menurut Peraturan Pembebanan Indonesia untuk Gedung (PPIUG) tahun 1983. Dalam Tugas Akhir ini, untuk beban gempa dilakukan dengan menggunkan peraturan terbaru Perencanaan Ketahanan Gempa Untuk Struktur Bangunan Gedung SNI-1726-2012. Rumus yang digunakan sebagai berikut.

$$
F_{i .}=\frac{W_{i} \times H_{i}{ }^{k}}{\sum W_{i} \times H_{i}{ }^{k}} \times V
$$

Keterangan:

$F_{i}=$ beban gempa pada lantai tingkat ke-i (ton)

$V=$ beban geser dasar nominal (ton)

$W_{i}=$ berat lantai tingkat ke-i (ton)

$H_{i}=$ ketinggian lantai tingkat ke-i (meter)

$K=$ eksponen yang terkait dengan perioda struktur

Sedangkan beban gempa dasar gedung yaitu beban horisontal lateral dihitung dengan persamaan:

$V=C_{s} \cdot W$

Keterangan:

$V=$ beban geser dasar nominal (ton)

$W=$ berat seismic efektif (ton)

$C_{s}=$ koefisien respons seismik

Pada Tugas Akhir ini Fakultas Teknik Universitas Moren yang menggunakan struktur rangka beton bertulang merupakan bangunan sebagai fasilitas pendidikan yang termasuk bangunan kelas VIII, dan masuk kedalam kategori risiko ke IV, sehingga Faktor keutamaan gempa $\left(I_{e}\right)=$ 1,5 dan $R=8$ (SNI-1726-2012).

$$
T_{x, y}=6,3 \sqrt{\frac{\sum W_{i} \times d_{i x, y}{ }^{2}}{g \times \sum F_{i . x, y} \times d_{i . x, y}}}
$$

Keterangan:

$T=$ waktu getar alami (detik)

$W_{i}=$ berat lantai ke-i $(\mathrm{kg})$

$F_{i \cdot x, y}=$ gaya gempa lantai $\mathrm{ke}-\mathrm{i}(\mathrm{kg})$

Waktu getar struktur dikontrol dengan caraT. Rayleigh dengan syarat selisih waktu getar $(T)$ dengan waktu getar hasil analisis vibrasi 3 dimensi, tipelat boleh melebihi $20 \%$.

\subsubsection{Perhitungan Tangga}

Gaya momen maksimum pada perhitungan tangga ini diperoleh dari hasil output menggunakan program SAP 2000 v.14 yang kemudian diolah dengan rumus sebagai berikut :

$$
\begin{aligned}
& M_{n} \quad=\frac{\boldsymbol{M u}}{\mathbf{0 , 8}} \\
& d \quad=h-C_{v}-\frac{\boldsymbol{o}}{2} \\
& M_{u} \quad=C_{c} \times z \\
& M_{u}=0,85 \times f_{c}{ }^{\prime} \times a \times b \times(d-a / 2) \\
& T s \quad=C_{c} \\
& A_{s} \times f y=0,85 \times f_{c}{ }^{\prime} \times a \times b
\end{aligned}
$$

Kontrol pembatasan luas tulangan minimum tangga dapat menggunakan rumus sebagai berikut :

As $\min =0,25 \% \times b \times h$

$\operatorname{Jarak}(S)=\frac{\frac{1}{4} \pi \times \emptyset^{2} \times 1.000}{A s}$

As tulangan bagi $=20 \% \times$ As tulangan utama

\subsubsection{Perhitungan Balok}

Balok merupakan salah satu komponen struktur yang menopang pelat lantai, beban yang terjadi pada balok akan ditopang oleh balok dan didistribusikan ke kolom. Perencanaan struktur balok mengacu buku "Desain Beton Bertulang, edisi ke-5 jilid 
1", penulis Jack C. McCormac. Satuan yang digunakan adalah A.S. Analisis desain balok, sebagai berikut :

\section{A. Desain penampang balok}

Rumus untuk menentukan luas penampang dan tulangan tarik pada balok sebagai berikut :

$$
\begin{aligned}
& w_{u}=1,2 D+1,6 L . \\
& M_{u}=\frac{w_{u} l^{2}}{8} .
\end{aligned}
$$$$
\rho_{\text {maks }}=0,75 \rho_{b} \text {. }
$$

$\beta=0,85$ (untuk beton maksimal fc' 4000 psi)

$$
\rho_{b}=\left(\frac{0,85 \beta_{1} f_{c}{ }^{\prime}}{f_{y}}\right)\left(\frac{87000}{87000+f_{y}}\right)
$$

$\rho_{\text {min }}=\frac{3 \sqrt{f_{c}^{\prime}}}{f_{y}}$, tipelat boleh kurang dari $\frac{200}{f_{y}}$

$\frac{M_{u}}{\emptyset b d^{2}}=\rho f_{y}\left(1-\frac{1}{17} \frac{\rho f_{y}}{f_{c^{\prime}}}\right)$.

$b d^{2}=$ (dimensibalok)

B. Desain tulangan tarik balok

Luas minimum tulangan yang diperlukan untuk menahan gaya tarik balok dihitung dengan rumus :

$A_{s}=\rho_{\text {maks }} b d$..

C. Desain tulangan tekan balok

Luas minimum tulangan yang diperlukan untuk menahan gaya tarik balok dihitung dengan rumus :

Rumus untuk menghitung luas penampang tulangan tekan yang dibutuhkan oleh balok sebagai berikut :

Asumsikan tulangan tekan telah leleh sehingga $A_{s 2}=A_{s}{ }^{\prime}$

$c=\frac{a}{0,85} \epsilon_{s}^{\prime}=\frac{c-d^{\prime}}{c}$, jika

$$
\begin{gathered}
A_{s 1}=A_{s}-A_{s 2} \\
a=\frac{A_{s 1} f_{y}}{0,85 f_{c}^{\prime} b}
\end{gathered}
$$

$\epsilon_{s}{ }^{\prime}>\frac{f_{y}}{29 \times 10^{6}}$ (tulangan tekan meleleh)

$\epsilon_{s}{ }^{\prime}<\frac{f_{y}}{29 \times 10^{6}}$ (tulangan tekan belum leleh)

Rumus lanjutan apabila tulangan tekan meleleh :

$$
\begin{gathered}
M_{n 1}=A_{s 1} f_{y} \\
M_{n 2}=A_{s}^{\prime} f_{y}\left(d-d^{\prime}\right) \\
M_{n}=M_{n 1}+M_{n 2} \\
M_{u}=\emptyset M_{n} . \\
A_{s m k s}=\emptyset \rho_{b} b d+A_{s}{ }^{\prime}
\end{gathered}
$$

Rumus lanjutan apabila tulangan tekan belum meleleh :

$$
f_{s}^{\prime}=\frac{\epsilon_{s}^{\prime}}{\frac{f_{y}}{29 \times 10^{6}}} f_{y}
$$

$$
A_{s 2}=\frac{A_{s}{ }^{\prime} f_{s}{ }^{\prime}}{f_{y}}
$$$$
A_{s 1}=A_{s}-A_{s 2}
$$$$
a=\frac{A_{s 1} f_{y}}{0,85 f_{c}{ }^{\prime} b}
$$$$
c=\frac{a}{0,85}
$$$$
\epsilon_{s}{ }^{\prime}<\frac{f_{y}}{29 \times 10^{6}}
$$$$
f_{s}^{\prime}=\frac{\epsilon_{s}{ }^{\prime}}{\frac{f_{y}}{29 \times 10^{6}}} f_{y}
$$$$
A_{s 2}=\frac{A_{s}^{\prime} f_{s}^{\prime}}{f_{y}}
$$$$
A_{s 1}=A_{s}-A_{s 2}
$$$$
a=\frac{A_{s 1} f_{y}}{0,85 f_{c}^{\prime} b}
$$$$
c=\frac{a}{0,85}
$$

$$
M_{u}=\emptyset\left[A_{s 1} f_{y}\left(d-\frac{a}{2}\right)+A_{s}^{\prime} f_{s}{ }^{\prime}\left(d-d^{\prime}\right)\right]
$$

$A_{s m k s}=\emptyset \rho_{b} b d+A_{s}{ }^{\prime} \frac{f_{s}{ }^{\prime}}{f_{y}}$.

D. Desain tulangan geser balok

Rumus untuk menghitung luas penampang dan jarak tulangan geser balok sebagai berikut :

$\varnothing V_{c}=2 \varnothing \sqrt{f_{c}} b_{w} d$.

Sengkang diperlukan jika,

$V_{u}>\frac{1}{2} \varnothing V_{c}$.

Rumus jika diperlukan sengkang,

$s=A_{v} f_{y} d / V_{s}$.

$V_{s}=\left(V_{u}-\emptyset V_{c}\right) / \varnothing$.

Jarak maksimum untuk menentukan

tulangan geser minimum, 
$s=A_{v} f_{y} / 50 b_{w}$.

Jarak maksimum $=\frac{d}{2} \leq 24$ inci jika,

$$
V_{s} \leq 4 \sqrt{f_{c}} b_{w} d
$$

Jarak maksimum $=\frac{d}{4} \leq 12$ inci jika,

$V_{s}>4 \sqrt{f_{c}} b_{w} d$.

$V_{s}$ tipelat boleh $>8 \sqrt{f_{c}} b_{w} d$.

Jarak praktis minimum mendekati 3 atau 4 inci.

\subsubsection{Perhitungan Kolom}

Bagian dalam struktur yang memiliki peran untuk menopang beban dari balok dan plat lantai yang kemudian disalurkan ke pondasi adalah kolom. Perhitungan kolom struktur mengacu pada buku "Desain Beton Bertulang, edisi ke-5 jilid 1", penulis Jack C. McCormac. Satuan yang digunakan adalah A.S. Analisis desain kolom, sebagai berikut :

\section{A. Desain dimensi kolom}

Rumus untuk menentukan dimensi kolom sebagai berikut :

$P_{u}=1,2 D+1,6 L$..

$P_{u}=\varnothing 0,80\left[0,85 f_{c}{ }^{\prime}\left(A_{g}-A_{s t}\right)+f_{y} A_{s t}\right]$.

(Persamaan ACI 10-2)

$A_{g}=$ luas penampang kolom

atau,

$A_{g}=\frac{P_{u}}{0,6 f_{c}{ }^{\prime}}$.

Asumsi yang digunakan,

$$
A_{s t}=0,02 A_{g}
$$

B. Desain tulangan kolom

Pada kolom yang hanya dibebani aksial, kebutuhan tulangan dihitung dengan rumus,

$P_{u}=1,2 D+1,6 L$..

$P_{u}=\emptyset 0,80\left[0,85 f_{c}{ }^{\prime}\left(A_{g}-A_{s t}\right)+f_{y} A_{s t}\right]$

$A_{s t}=$ luas tulangan kolom

Pada kolom yang dibebani aksial dan lentur, kebutuhan tulangan dihitung dengan rumus,

$\rho=\frac{\gamma_{h}}{h}$.

$e=\frac{M_{u}}{P_{u}}$.

$\frac{\emptyset P_{n}}{A_{g}} \frac{e}{h}=$ dengan interpolasi grafik maka didapatkan $\rho$
$A_{s}=\rho b d$.

C. Desain tulangan geser kolom

Rumus untuk menghitung luas penampang dan jarak tulangan geser kolom sebagai berikut :

$\varnothing V_{c}=2 \varnothing\left(1+\frac{N_{u}}{2000 A_{g}}\right) \sqrt{f_{c}{ }^{\prime}} b_{w} d$.

Sengkang diperlukan jika,

$V_{u}>\frac{1}{2} \varnothing V_{c}$.

Rumus jika diperlukan sengkang,

$s=A_{v} f_{y} d / V_{s}$.

$V_{s}=\left(V_{u}-\varnothing V_{c}\right) / \varnothing$..

Jarak maksimum untuk menentukan tulangan geser minimum,

$$
s=A_{v} f_{y} / 50 b_{w}
$$

Jarak maksimum $=\frac{d}{2} \leq 24$ inci jika,

$V_{s} \leq 4 \sqrt{f_{c}{ }^{\prime}} b_{w} d$.

Jarak maksimum $=\frac{d}{4} \leq 12$ inci jika,

$V_{s}>4 \sqrt{f_{c}{ }^{\prime}} b_{w} d$.

$V_{s}$ tipelat boleh $>8 \sqrt{f_{c}{ }^{\prime}} b_{w} d$

\subsubsection{Perhitungan Pondasi Tiang Pancang}

Rumus-rumus yang digunakan antara lain :

1. Perhitungan daya dukung tiang pancang berdasarkan hasil sondir (Metode Schmertmann-Nottingham, 1975)

$$
Q p=\frac{q_{c 1}+q_{c 2}}{2} \times A p \text {. }
$$

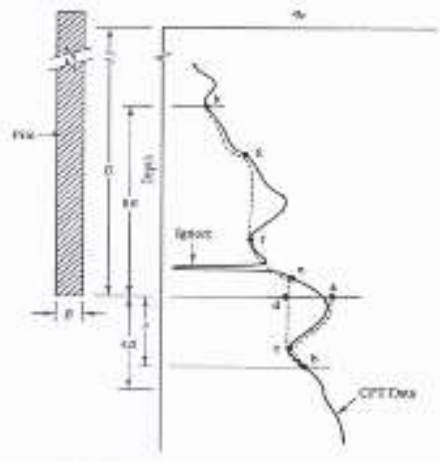

Gambar Error! No text of specified style in document..2 Perhitungan Data Dukung Ujung 
Sumber : Manual Pondasi Tiang Edisi 3 (2005)

Untuk mendapatkan daya dukung selimut tiang maka digunakan rumus berikut:

$$
Q_{s}=K_{s, c}\left[\sum_{z=0}^{8 D} \frac{z}{8 D} \cdot f_{s} \cdot A_{s}+\sum_{z=8 D}^{L} \cdot f_{s} \cdot A_{s}\right]
$$

Faktor koreksi gesekan selimut tiang pada sondir listrik dapat dilihat pada Gambar 2.3 dan pada sondir mekanis pada Gambar 2.4

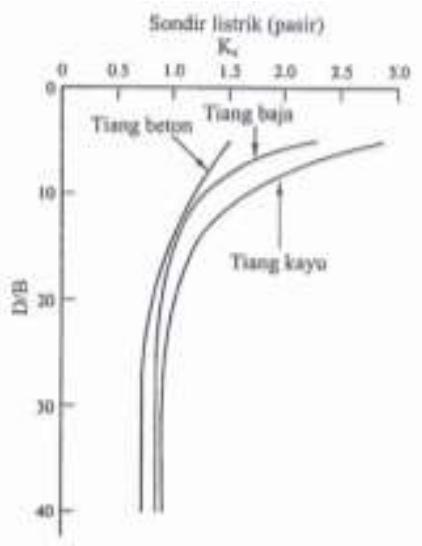

Gambar Error! No text of specified style in document..3 Faktor Koreksi Gesekan Selimut Tiang pada Sondir Listrik

Sumber : Manual Pondasi Tiang Edisi 3 (2005)

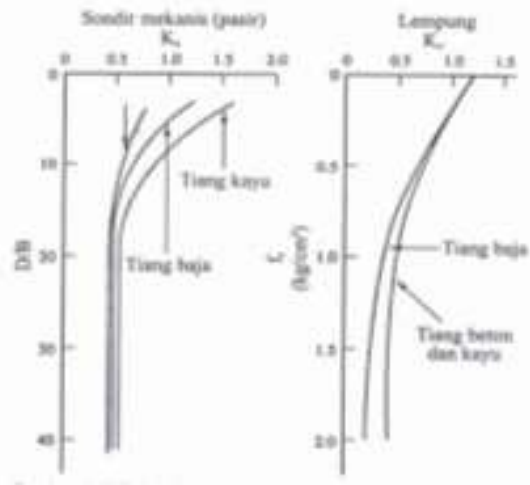

Gambar Error! No text of specified style in document..4 Faktor Koreksi Gesekan Selimut Tiang pada Sondir Mekanis

Sumber : Manual Pondasi Tiang Edisi 3
Kapasitas daya dukung ultimit ditentukan dengan persamaan sebagai berikut :

$\mathrm{Q}_{\mathrm{u}}=\mathrm{Q}_{\mathrm{p}}+\mathrm{Q}_{\mathrm{s}}$

Keterangan :

$\mathrm{Q}_{\mathrm{u}}=$ kapasitas daya dukung aksial ultimit tiang pancang (ton)

$\mathrm{Q}_{\mathrm{p}}=$ kapasitas tahanan di ujung tiang (ton)

$\mathrm{Q}_{\mathrm{s}}=$ kapasitas tahanan kulit (ton)

Besarnya faktor aman yang telah banyak digunakan untuk perancangan pondasi tiang pancang, sebagai berikut

$\mathrm{Q}_{\mathrm{a}}=\frac{Q u}{2,5}$

Keterangan :

$\mathrm{Q}_{\mathrm{a}}=$ kapasitas tiang ijin (ton)

$\mathrm{Q}_{\mathrm{u}}=$ kapasitas daya dukung aksial ultimit tiang pancang (ton)

2. Perhitungan daya dukung tiang pancang berdasarkan Data SPT/ Standard Penetration Test (Metode Meyerhof, 1976)

Daya dukung ujung tiang dihitung dengan menggunakan rumus:

$$
\begin{aligned}
& C_{N}=\frac{2}{1+\frac{\sigma^{\prime}{ }_{v}}{\sigma_{r}}} \\
& N^{\prime}{ }_{60}=C_{N} \times N_{60} \\
& q_{p}=3 \times N^{\prime}{ }_{60} \times 100 \\
& Q_{p}=q_{p} / A_{p}
\end{aligned}
$$

\section{Daya dukung selimut tiang pancang dihitung menggunakan rumus}

$f_{s}=\frac{100}{50} \times N_{S P T}$

$Q_{s}=f_{s} \times A_{s}$

Daya dukung tiang pancang:

$Q_{u}=\left(Q_{p}+Q_{s}\right) / 3$

(2005) 


\subsubsection{Perhitungan Pilecap}

Perhitunganpilecap mengacu pada

buku "Desain Pondasi Tahan Gempa".

Penulis Anugrah Pamungkas dan Erny

Harianti. Satuan yang digunakan adalah

SI. Analisis desain pilecap, sebagai berikut$$
B^{\prime}=l_{p}-l_{k}
$$

$$
\begin{gathered}
q^{\prime}=2400 A_{g} \\
M_{u}=2\left(\frac{P_{u}}{4}\right) s-0,5 q B^{2} \\
\varphi M_{n}=\varphi A_{s} f_{y}\left(d-\frac{a}{2}\right) \\
a=\frac{A_{s} f_{y}}{0,85 f_{c}{ }^{\prime} b}
\end{gathered}
$$

\subsubsection{Perhitungan TieBeam}

Menurut buku "Desain Pondasi Tahan Gempa" yang ditulis oleh Anugrah Pamungkas dan Erny Harianti, satuan yang digunakan adalah SI. Berikut rumus yang digunakan pada perhitungan perencaantie beam:

$$
\begin{aligned}
& A_{s \min }=\frac{\sqrt{f_{c}}}{4 f_{y}} b d \\
& A_{s \min }=\frac{1,4 b d}{f_{y}} \\
& \Delta_{M}=\frac{6 E I \Delta_{s}}{L_{s}{ }^{2}} \\
& a \quad=\frac{A_{s} f_{y}}{0,85 f_{c}^{\prime} b} \\
& M_{n} \quad=A_{s} f_{y}\left(d-\frac{a}{2}\right)
\end{aligned}
$$

\subsection{Asumsi-asumsi}

Asumsi-asumsi yang digunakan dalam perencanaan gedung ini adalah:

1. Struktur utama dibuat dari konstruksi beton bertulang dan atap menggunakan pelat beton,

Beban mati yang digunakan: (PPIUG 1983)

$\begin{array}{lll}\text { Beton bertulang } & = & 2400 \\ \mathrm{~kg} / \mathrm{m}^{3} & & \\ \text { Pasir } & = & 1800 \\ \mathrm{~kg} / \mathrm{m}^{3} & & \end{array}$

Spesi dengan tebal $1 \mathrm{~cm}=21 \mathrm{~kg} / \mathrm{m}^{2}$

Pasangan bata merah $\quad=250 \mathrm{~kg} / \mathrm{m}^{2}$

Plafon dan penggantung $=18 \mathrm{~kg} / \mathrm{m}^{2}$

Keramik $\quad=24 \mathrm{~kg} / \mathrm{m}^{2}$

Beban hidup yang digunakan: (PPIUG 1983 Tabel 3.1)

a. Gudang, Janitor, Lavatory, Kantin, Selasar $=250 \mathrm{~kg} / \mathrm{m}^{2}$

b. Tangga dan bordes $=300 \mathrm{~kg} / \mathrm{m}^{2}$

c. Lantai ruang perpustakaan, ruang TU,Ruang dosen,

Ruang dekan, Ruang rapat, Ruang kelas,

Ruang BEM, Ruang senat, Koperasi, Ruang komputer $=400 \mathrm{~kg} / \mathrm{m}^{2}$

d. Atap $=100 \mathrm{~kg} / \mathrm{m}^{2}$

Koefisien reduksi beban hidup untuk gempa sebesar 0,5 sedang untuk portal dan balok induk sebesar 0,9

Tipe balok induk yang direncanakan yaitu 450 x 700 dan 350 x 500

2. Sedangkan tipe balok anak yang direncanakan adalah 350 × 600 dan $300 \times 450$.

3. Kolom

Tipe kolom yang direncanakan adalah kolom persegi dengan dimensi $800 \mathrm{~mm} \times$ $800 \mathrm{~mm}$. Jika ternyata hasil SAP 2000 v14 tipelat memenuhi syarat, maka dimensi akan diubah agar memenuhi syarat teknis dan ekonomis.

Beban merata $(q)$ yang berasal dari beban pelat ekivalen maupun berat sendiri balok dan pelat akan diterima oleh balok anak dan atau balok induk. Sistem pembebanan didasarkan pada anggapan bahwa balok anak dan balok induk merupakan konstruksi yang menerima beban secara bersamaan. Beban-beban tersebut akan didistribusikan ke kolom oleh balok yang kemudian diteruskan ke pondasi,

4. Tebal dinding pasangan batu bata setengah batu $15 \mathrm{~cm}$, 
5. Aplikasi yang digunakan untuk perhitungan mekanika adalah SAP 2000 v. 14,

6. Pondasi yang direncanakan adalah tiang pancang dengan mengacu kemampuan daya dukung tanah juga lapisan tanah di daerah Kranggan Semarang.

\section{Metodologi penelitian}

\subsection{Tinjauan Umum}

Dalam perencanaan khususnya untuk struktur Gedung Fakultas Teknik Sipil Universitas MorenSemarang terdapat beberapa langkah yang perlu dilakukan. Berikut ini adalah langkah-langkahnya yaitu:

1. Survei Lokasi

2. Design Arsitektural

3. Pembuatan Rencana Kerja dan Syarat Syarat (RKS)

4. Analisis dan perencanaan struktur

5. Gambar struktur

6. Perhitungan RAB

7. Pembuatan time schedule

\section{Analisis dan Pembahasan}

\subsection{Perhitungan Plat Lantai}

Analisa perhitungan pelat lantai dan pelat atap disesuaikan dengan beban yang dipikul tiap lantai dan bentuk pelat mengikuti bentuk denah balok. Struktur pelat seluruhnya menggunakan beton konvensional dengan material bahan menggunakan beton $\mathrm{K}-350\left(f_{c}{ }^{\prime}=29,05 \mathrm{MPa}\right)$, dan baja tulangan $f_{y}=240 \mathrm{MPa}$. Perencanaan pelat lantai untuk lantaiground, tebal pelat lantai adalah 200 mm dengan penulangan arah-x $\varnothing 10-75$ dan arah-y Ø10-75.Perencanaan pelat lantai untuk lantai 1-5, tebal pelat lantai adalah $120 \mathrm{~mm}$ dengan penulangan arah-x $\varnothing 10-$ 100 dan arah-y Ø10-75. Sedangkan perencanaan pelat lantai untuk lantai $1-5$, tebal pelat lantai adalah $120 \mathrm{~mm}$ dengan penulangan arah-x Ø10-150 dan arah-y Ø10-125.
Pada setiap lantai di gedung terdapat tangga yang memiliki dimensi tipikal. Posisi tangga yaitu:

1. Tebal Plat $1=0,15 \mathrm{~m}$

2. Panjang Tangga $\quad=3 \mathrm{~m}$

3. Tinggi Tangga $=4 \mathrm{~m}$

4. Lebar anak tangga $\quad=3 \mathrm{~m}$

5. Panjang bordes $\quad=2,5 \mathrm{~m}$

6. Tinggi bordes $\quad=2 \mathrm{~m}$

7. Optrede/tanjakan $\quad=0,1818 \mathrm{~m}$

8. Antrede/injakan $\quad=0,3 \mathrm{~m}$

9. Jumlah anak tangga $=21$ buah

10. Beban rumah tinggal $=300 \mathrm{~kg} / \mathrm{m}^{3}$

11. Berat jenis beton $=2400 \mathrm{~kg} / \mathrm{m}^{2}$

12. Sudut $(\alpha) \quad=31,22^{\circ}$

Dari hasil perhitungan mekanika teknik menggunakan program komputer SAP 2000 v.14 maka didapatkan desain struktur tangga. BordesDengan tebal $150 \mathrm{~mm}$ digunakan tulangan D13-175 mm.Plat tangga Dengan tebal $150 \mathrm{~mm}$ digunakan tulangan utama D13-175 mm.

\subsection{Perhitungan Gaya Gempa}

Berdasarkan SNI 03-1726-2012analisis beban gempa pada struktur gedung direncanakan dengan tujuan Menghindari terjadinya korban jiwa manusia oleh runtuhnya gedung akibat gempa yang kuat. Membatasi kerusakan gedung akibat gempa ringan sampai sedang, sehingga masih dapat diperbaiki. Mengurangi ketipelatnyamanan penghunian bagi penghuni gedung ketika terjadi gempa ringan sampai sedang.

Tabel 4.1Distribusi gaya geser horisontal total akibat gempa arah $\mathrm{x}$ dan $\mathrm{y}$

\begin{tabular}{|c|r|r|}
\hline Lantai & Fi x $(\mathrm{kg})$ & Fi y $(\mathrm{kg})$ \\
\hline ground & \multicolumn{1}{c|}{0} & 0 \\
\hline 1 & $\mathbf{2 0 2 3 , 8}$ & $\mathbf{1 8 2 7}$ \\
\hline 2 & $\mathbf{3 5 2 0}$ & $\mathbf{3 1 7 9}$ \\
\hline 3 & $\mathbf{4 9 3 6}$ & $\mathbf{4 4 6 0}$ \\
\hline 4 & $\mathbf{6 2 8 9}$ & $\mathbf{5 6 8 5}$ \\
\hline 5 & $\mathbf{7 6 0 9}$ & $\mathbf{6 8 7 9}$ \\
\hline atap & $\mathbf{5 6 2 1}$ & $\mathbf{5 0 8 3}$ \\
\hline
\end{tabular}

\subsection{Perhitungan Tangga}

\subsection{Perencanaan Balok dan Kolom}


Perencanaan balok dan kolom dilakukan dengan melakukan asumsi terlebih dahulu, setelah asumsi yang ada dilakukan per-modelan dengan menggunakan SAP v14. Hasil reaksi dan gaya oleh SAP v14 akan dilakukan perhitungan penulangan meng-gunakan rumus.

Tabel 4.2Hasil Perhitungan Balok

\begin{tabular}{|c|c|c|c|}
\hline $\begin{array}{c}\text { Tipe } \\
\text { Balok }\end{array}$ & $\begin{array}{c}\text { Dimensi } \\
\text { Balok }\end{array}$ & $\begin{array}{c}\text { Tulangan } \\
\text { Tumpuan }\end{array}$ & $\begin{array}{c}\text { Tulangan } \\
\text { Lapangan }\end{array}$ \\
\hline B1 & $450 \times 700$ & 10 D 22 & 8 D 22 \\
\hline B2 & $350 \times 500$ & 9 D 19 & 8 D 19 \\
\hline B3 & $350 \times 600$ & 7 D 19 & 9 D 19 \\
\hline B4 & $300 \times 450$ & 6 D 19 & 7 D 19 \\
\hline
\end{tabular}

Tabel 4.3Hasil Perhitungan Kolom

\begin{tabular}{|c|c|c|c|}
\hline $\begin{array}{c}\text { Tipe } \\
\text { Kolom }\end{array}$ & $\begin{array}{c}\text { Dimensi } \\
\text { Kolom }\end{array}$ & $\begin{array}{c}\text { Tulangan } \\
\text { Utama }\end{array}$ & $\begin{array}{c}\text { Tulangan } \\
\text { Sengkang }\end{array}$ \\
\hline K1 & $800 \times 800$ & 22 D 22 & D 10 - 150 \\
\hline
\end{tabular}

\subsection{Perencanaan Pondasi}

Pondasi yang direncanakan adalah pondasi tiang pancang.Perhitungan daya dukung pondasi tiang pancang untuk perencanaan struktur gedung Fakultas Teknik Universitas MorenberdasarkanCPT (Cone Penetration Test)dan SPT (Standard Penetration Test) dari laboratorium mekanika tanah Unika Soegijapranata.

Ukuran pondasi tiang pancangdiameter $50 \mathrm{~cm}$ dengan kedalaman pondasi $18 \mathrm{~m}$ dari permukaan tanah. Dari hasil perhitungan didapatkan daya dukung ijin pondasitiang pancang 770,4443 ton.

\subsection{Perencanaan Pilecap}

Desain pilecap yang digunakan ada lima macam, yaitu Terdapat 2 jenis pilecap yang digunakan yaitu pilecap dengan 9 tiang pancang (PC1), dan8 tiang (PC2).

\subsection{Perencanaan Tie Beam}

\begin{tabular}{|c|c|c|c|}
\hline $\begin{array}{c}\text { Tipe } \\
\text { Tie } \\
\text { Beam }\end{array}$ & Dimensi & $\begin{array}{c}\text { Tulangan } \\
\text { Utama }\end{array}$ & $\begin{array}{c}\text { Tulangan } \\
\text { Sengkang }\end{array}$ \\
\hline TB1 & $400 \times 600$ & 8 D 19 & D10 -100 \\
\hline TB2 & $300 \times 450$ & 6 D 19 & D10 -150 \\
\hline
\end{tabular}

\section{RAB dan Kurva-S}

Dalam analisis biaya konstruksi ini dijelaskan mengenai perhitungan harga satuan pekerjaan. Harga satuan pekerjaan ini berdasarkan HSPK tahun terbaru yang bersumber dari SNI 2012. Pada analisa biaya konstruksi ini meliputi data harga satuan barang, upah, alat, maupun material. Dari harga satuan pekerjaan dilakukan perhi-tungan volume tiap-tiap pekerjaan, khu-susnya struktur. Sehingga diperoleh biaya yang dibutuhkan dalam pembangunan struk-tur gedung. Total biaya struktur adalah Rp. 36.239.801.000,dengan waktu pekerjaan selama sembilan bulan yaitu dari bulan Juni 2018 hingga bulan Februari 2019.

\section{Kesimpulan dan Saran}

\section{a. Kesimpulan}

1. Struktur atap menggunakan lantai beton dengan mutu beton K350.

2. Pelat lantai untuk lantai dasar menggunakan pelat setebal $20 \mathrm{~cm}$ dan lantai 1 - atap menggunakan pelat setebal $12 \mathrm{~cm}$

3. Desain struktur portal utama adalah sebagai berikut :

a. Balok $(\mathrm{K}-350) f^{\prime}{ }_{c}=29 \mathrm{MPa}, f_{y}=240$ $\mathrm{MPa}$

1) $\mathrm{B} 1=(45 \times 70) \mathrm{cm}$

2) $\mathrm{B} 2=(35 \times 50) \mathrm{cm}$

3) $\mathrm{B} 3=(35 \times 60) \mathrm{cm}$

4) $\mathrm{B} 4=(30 \times 45) \mathrm{cm}$

5) $\mathrm{B}^{\prime}=(45 \times 70) \mathrm{cm}$

6) $\mathrm{B}^{\prime}{ }^{\prime}=(35 \times 50) \mathrm{cm}$

7) $\mathrm{B}$ Tangga $=(30 \times 40) \mathrm{cm}$

b. Kolom $(\mathrm{K}-350) f^{\prime}{ }_{c}=29 \mathrm{MPa}, f_{y}=$ $240 \mathrm{MPa}$

1) $\mathrm{K} 1=(80 \times 80) \mathrm{cm}$

c. Tie Beam $(\mathrm{K}-350) f^{\prime}{ }_{c}=29 \mathrm{MPa}, f_{y}=$ $240 \mathrm{MPa}$ 
1) $\mathrm{TB} 1=(40 \times 60) \mathrm{cm}$

2) $\mathrm{TB} 2=(30 \times 45) \mathrm{cm}$

d. Pondasi (K-450)

Menggunakan pondasi tiang pancang dengan bentuk lingkaran dengan diameter $50 \mathrm{~cm}$ dengan kedalaman 18 meter.

1. Perhitungan struktur ini menggunakan SAP 2000 Version 17.2.0 Build 1140

2. Hasil perhitungan rencana anggaran biaya struktur gedung ini + profit dan PPN sebesar Rp 36.239.801.000-

\section{b. Saran}

Saran yang bisa digunakan untuk menyempurnakan tugas akhir perencanaan ini seperti :

1. Angka-angka asumsi yang akan digunakan untuk membebani struktur harus diperhatikan agar mengurangi kesalahan dalam perhitungan. Sedangkan untuk dimensi struktur (balok, kolom, pelat) sebaiknya dicek terlebih dahulu dengan menggunakan program apakag sudah memenuhi persyaratan keamanan

2. Memasukkan angka ke dalam program SAP dengan cermat dan teliti agar tipelat terjadi kesalahan

3. Dalam perhitungan anggaran biaya juga harus diperhatikan supaya nilai dari gedung sesuai dengan realita yang ada.

\section{DAFTAR PUSTAKA}

GEC FT Unpar, 2005, Manual Pondasi Tiang Edisi 3, Bandung

McCormac, J.C., (2004), "Desain Beton Bertulang Edisi Kelima Jilid 1", Erlangga, Jakarta.

McCormac, J.C., (2004), "Desain Beton Bertulang Edisi Kelima Jilid 2", Erlangga, Jakarta.
Pamungkas, Anugrah. dan Harianti, Erny., (2013), Desain Pondasi Tahan Gempa, Andi, Yogyakarta.

PPIUG-1983, (1983), Pedoman Peraturan Pembebanan Indonesia untuk Rumah dan Gedung,

SNI 1726-2012, (2012), Tata Cara Perencanaan Ketahanan Gempa untuk Struktur Bangunan Gedung dan Non Gedung, Badan Standardisasi Nasional, Jakarta

Suryoatmono, Bambang .1990 . Beton Bertulang Suatu Pendekatan Dasar. Bandung: PT. Eresco.

SNI 03-1726-2012 